\title{
USO DO FOGO NA AGRICULTURA: LEGISLAÇÃO, IMPACTOS AMBIENTAIS E REALIDADE NA AMAZÔNIA.
}

Ana Luísa Alves Cabral ${ }^{1}$

Luiz Otávio Moras Filho²

Luís Antônio Coimbra Borges ${ }^{3}$

RESUMO: O presente trabalho consiste em um estudo da legislação Brasileira a respeito do uso do fogo como uma ferramenta para a agricultura. O fogo traz uma série de facilidades e benefícios ao produtor, já que prepara a terra para o cultivo e é barato e acessível. Porém, ao sair do controle, o fogo, gera muitos impactos ao ambiente e a sociedade. Na Amazônia o problema é ainda mais grave, pois o uso do folgo é cultural e pra muitos produtores isolados, a única opção, visto que não é possível ter acesso às novas tecnologias e ferramentas. Com auxílio da pesquisa bibliográfica, este trabalho teve como objetivo conhecer a situação do fogo na Amazônia assim como os impactos causados pelo mesmo. O trabalhou mostrou que o problema do uso do fogo na Amazônia é grave, pois ainda não existem tecnologias acessíveis aos pequenos agricultores isolados da região e o fogo continua sendo utilizado sem as devidas precauções. Grandes incêndios acontecem frequentemente na região e os mesmos têm gerado muitos impactos no meio ambiente e na sociedade.

Palavras-chave: Uso do fogo. Queimadas na Amazônia. Impactos ambientais.

\footnotetext{
${ }^{1}$ Mestranda em Engenharia Florestal, UFLA. analuisa.cabral@outlook.com.

${ }^{2}$ Mestrando em Engenharia Florestal, UFLA. lomf_22@hotmail.com.

${ }^{3}$ Professor Adjunto do Departamento de Ciências Florestais, UFLA. luis.borges@dcf.ufla.br.
} 


\section{INTRODUÇÃO}

O Brasil é a nação com a maior diversidade de espécies no mundo com seis biomas terrestres e três grandes ecossistemas marinhos, além de pelo menos 103.870 espécies animais e 43.020 espécies vegetais atualmente conhecidas no país (MMA, 2011).

O uso do fogo como ferramenta agrícola gera diversos impactos ao ambiente, entre eles a perda da biodiversidade. Vários motivos levam a degradação ambiental, dentre os principais estão o corte, incêndios e atividades agropastoris. Os desmatamentos e as queimadas são duas das maiores questões ambientais enfrentadas pelo Brasil atualmente. Embora distintas, são práticas tradicionalmente associadas, pois em sequência à derrubada da vegetação, quase sempre há a queima do material vegetal (GONÇALVES et al, 2012).

A legislação Brasileira a respeito do uso do fogo vem evoluindo ao longo dos anos, na qual é permitido a Queima Controlada em alguns casos mediante autorização do órgão responsável. Porém, mesmo com a legislação existente a falta de controle e fiscalização ainda permite que os incêndios florestais se alastrem e destruam a biodiversidade.

Na Amazônia, o uso do fogo é tradicional e de difícil substituição, pois se trata de um método barato e acessível aos locais mais remotos da região. Logo é importante conhecer a legislação que regulamenta o uso do fogo, os impactos causados e principalmente ferramentas alternativas.

\section{OBJETIVOS}

O objetivo desse trabalho é levantar a legislação Brasileira sobre o uso do fogo. Assim como analisar as queimadas feitas na Amazônia e os impactos causados pelas mesmas. 


\section{MATERIAL E MÉTODOS}

Este trabalho baseou-se em pesquisas bibliográficas. A pesquisa bibliográfica pode ser considerada o primeiro passo da pesquisa científica, buscando harmonizar os vários pontos de vista, gerando uma visão sensata e útil, sob o aspecto informativo, do problema em estudo (BORGES, 2009).

Para Malhotra (2001), o objetivo principal dos trabalhos com enfoque exploratório e bibliográfico é possibilitar a compreensão do problema enfrentado pelo pesquisador, definindo-o com maior precisão e identificando cursos relevantes de ação antes que se possa desenvolver uma abordagem. Em relação aos procedimentos técnicos, é uma pesquisa bibliográfica em que, segundo Gil (2008), se utiliza material já elaborado, constituído, principalmente, de livros e periódicos científicos.

\section{LEGISLAÇÃO SOBRE O USO DO FOGO}

O primeiro Código Florestal Brasileiro de 1934 (Decreto № 23.793/34) proibiu o uso do fogo em qualquer tipo de vegetação, além da proibição da soltura de balões. E ainda o considerou como crime florestal.

Art. 83. Constituem crimes florestais:

a) fogo posto em florestas do domínio publico, ou da propriedade privada; pena: prisão até três anos, e multa;

b) fogo posto em produtos, ou subprodutos florestais, ainda não retirados das florestas onde foram obtidos ou elaborados; pena: prisão até dois anos e multa;

c) dano causado aos parques nacionais, estaduais ou municipais, e ás florestas protetoras e remanescentes, ou ás plantações, por meio que não o fogo; pena: detenção até um ano e multa. (BRASIL, 1934) 
Em 1965 foi instituído o Novo Código Florestal (Lei no 4.771), em que o uso do fogo continuou sendo proibido nas florestas e demais formas de vegetação, porém com a exceção do seu artigo 27.

Art. 27. É proibido o uso de fogo nas florestas e demais formas de vegetação.

Parágrafo único. Se peculiaridades locais ou regionais justificarem o emprego do fogo em práticas agropastoris ou florestais, a permissão será estabelecida em ato do Poder Público, circunscrevendo as áreas e estabelecendo normas de precaução. (BRASIL, 1965)

O parágrafo único do artigo 27 foi posteriormente regulamentado pelo Decreto ํㅡ 2661 de 1998. Em 28 artigos, o decreto focaliza a questão da queima controlada, das medidas de precaução, o ordenamento territorial do emprego do fogo, a suspensão temporária e a redução gradativa do emprego do fogo.

O decreto 2.661/98 também conceituou queima controlada e incêndio florestal. A primeira sendo o emprego do fogo como fator de produção e manejo em atividades agropastoris ou florestais, e para fins de pesquisa científica e tecnológica, em áreas com limites físicos previamente definidos. $E$ os incêndios florestais como todo fogo não controlado em floresta ou qualquer outra forma de vegetação.

Além das definições o decreto regulamentou em quais situações a Queima Controlada poderia ser utilizada em seus artigos $2^{\circ}$ e $3^{\circ}$.

Art $2^{\circ}$ É permitido o emprego do fogo em práticas agropastoris e florestais, mediante Queima Controlada.

Art $3^{\circ}$ O emprego do fogo mediante Queima Controlada depende de prévia autorização, a ser obtida pelo interessado junto ao órgão do Sistema Nacional do Meio Ambiente - SISNAMA, com atuação na área onde se realizará a operação. (BRASIL, 1998)

Várias medidas de proteção são exigidas para a execução da Queima Controlada, como por exemplo, providenciar pessoal treinado e a construção de aceiros. E mesmo com a queima autorizada o órgão ambiental competente pode ainda suspender a autorização, caso julgue necessário. 
O atual Código Florestal (Lei no 12.651/ 2012) manteve a proibição do uso do fogo na vegetação, porém com algumas exceções.

Art. 38. É proibido o uso de fogo na vegetação, exceto nas seguintes situações:

I - em locais ou regiões que justifiquem o emprego do fogo em práticas agropastoris ou florestais, mediante prévia aprovação do órgão estadual ambiental;

II - emprego da queima controlada em Unidades de Conservação, em conformidade com o plano de manejo, visando ao manejo conservacionista da vegetação nativa, cujas características ecológicas estejam associadas evolutivamente à ocorrência do fogo;

III - atividades de pesquisa científica vinculada a projeto de pesquisa devidamente aprovado pelos órgãos competentes. (BRASIL, 2012)

O novo Código inovou ao incluir o uso da Queima Controlada nas Unidades de Conservação nas quais exista um plano de manejo, privilegiando o Cerrado Brasileiro que é um bioma cujas características ecológicas estão associadas à ocorrência do fogo.

Outra importante novidade no Código Florestal vigente é seu artigo 40, no qual é incumbido ao Governo Federal o estabelecimento de uma Política Nacional de Manejo e Controle de Queimadas, Prevenção e Combate aos Incêndios Florestais. Essa medida pode gerar novos mecanismos e instrumentos para melhor fiscalização e controle do fogo no país.

\section{IMPACTOS GERADOS PELAS QUEIMADAS}

As queimadas trazem consigo múltiplos problemas, como a poluição do ar, a problemática do efeito estufa, efeito direto sobre a flora a fauna, saúde do ser humano, sustentabilidade agrícola e também trazem impactos sociais. Logo é importante analisar cada um desses impactos separadamente a fim de entendê-los melhor.

\subsection{Efeito Estufa}


Na Amazônia brasileira, o desmatamento provoca a emissão de aproximadamente 200 milhões de toneladas de carbono para atmosfera cada ano (Houghton et al., 2000), o que representa $2,5 \%$ da emissão global de carbono. Porém, esse dado envolve toda emissão de desmatamento não somente aquele proveniente do uso do fogo.

A queimada consiste na queima de biomassa, quantidade de matéria orgânica produzida numa determinada área de um terreno, produzindo água e dióxido de carbono:

$$
[\mathrm{CH} 2 \mathrm{O}]+\mathrm{O} 2 \Rightarrow \mathrm{H} 2 \mathrm{O}+\mathrm{CO} 2
$$

Onde [CH2O] representa a matéria orgânica queimada. Juntamente com o CO2 podem-se produzir nas queimadas: monóxido de carbono (CO), óxidos de nitrogênio (NO e NO2) e hidrocarbonetos (compostos contendo essencialmente carbono e hidrogênio).

De acordo com Milori (2004) os principais gases naturais responsáveis por este efeito são: vapor de água $(\mathrm{H} 2 \mathrm{O})$, dióxido de carbono $(\mathrm{CO} 2)$, metano $(\mathrm{CH} 4)$, óxido nitroso (N2O) e ozônio (O3).

O grande incêndio de Roraima de 1998 liberou, através da combustão, de 17,9 a 18,3 x 106 toneladas de carbono equivalente ao carbono de CO2, dos quais 67\% (12,0 a 12,3 x 106 de carbono) foram provenientes de queimadas na floresta primária (BARBOSA, et al 1999). Os carbonos equivalentes ao carbono do dióxido de carbono são utilizados para comparar as emissões de vários gases de efeito estufa baseado no potencial de aquecimento global de cada gás em um horizonte de tempo de 100 anos (FEARNSIDE, 2005).

\subsection{Fauna e Flora}

Muitas vezes as queimadas fogem do controle do produtor e destroem remanescentes florestais e outros tipos de cobertura vegetal, os incêndios fragmentam a paisagem, alteram a biodiversidade e afetam a dinâmica dos ecossistemas (EMBRAPA, 1991). 
Outro impacto importante do uso do fogo é o gradativo aumento da vulnerabilidade das florestas, após os eventos de incêndios. Com o efeito das chamas, que tenham conseguido penetrar no interior de uma floresta, morrem algumas árvores adultas e a consequente abertura do dossel, resulta na redução e perda da capacidade de manutenção da umidade no interior da mata. Aumenta, então, a inflamabilidade da área e a floresta se torna progressivamente mais susceptível à incidência de novos incêndios (NEPSTAD et al., 1998).

Os efeitos do incêndio rasteiro sobre a fauna da floresta amazônica são potencialmente grandes, mas raramente estudados. As populações de animais que se movimentam lentamente são severamente prejudicadas pelo fogo. A morte de árvores frutíferas provocada pelo fogo pode levar à falta de alimentos para os mamíferos frutívoros da floresta da mesma maneira como secas severas levam à falta de alimento e à redução de suas populações. As espécies de mamíferos da floresta que dependem de frutos para sua alimentação, e que podem sofrer redução populacional como um resultado do incêndio florestal incluem antas, grandes macacos, porcos selvagens, veados e cutias (NEPSTAD et al., 1991).

\subsection{Mudanças no regime hidrológico}

A redução da massa florestal e a fumaça emitida podem afetar o regime de chuvas local, provocando uma redução nos níveis de precipitação (Nobre et al., 1991; Rosenfeld, 1999; Andreae et al., 2004). O consequente agravamento dos efeitos dos períodos de seca estabelece, assim, uma nova relação de causa e efeito bastante forte e comprometedora da perenidade da floresta (NEPSTAD et al., 1998).

A mortalidade de árvores conduz a uma redução na área foliar, o que diminui a quantidade de água que deixa a floresta por meio da transpiração. A floresta amazônica transpira tanta água que desempenha um papel importante no sistema do clima regional (NEPSTAD et al., 1991).

\subsection{Saúde do Ser Humano}


As doenças provocadas pela fumaça das queimadas e seus constituintes, são aquelas comuns das vias respiratórias, agravadas pelas cancerígenas dioxinas (quando existe plástico envolvido) e pelo efeito do calor emanado do fogo, que pode ultrapassar os 600 graus centígrados (GIGANTE et AL, 2007).

Os habitantes da Amazônia rural respiram um ar mais poluído, durante semanas, do que aquele do centro de São Paulo. A fumaça invade os centros urbanos e enviam dezenas de milhares de pessoas para clínicas de saúde com sintomas de bronquite, asma e outras doenças respiratórias. De acordo com o Ministério da Saúde brasileiro, duas vezes mais pacientes são atendidos nos hospitais com problemas respiratórios durante os meses de pico de queimadas, se comparado aos outros meses do ano (NEPSTAD et al., 1991).

\subsection{Sustentabilidade Agrícola}

O fogo é tradicionalmente utilizado como um promotor do aumento da fertilidade dos solos, pois provoca a queima da cobertura vegetal existente e, apesar de parte dos nutrientes serem volatizados, uma boa parte é depositada no solo sob a forma de cinzas, aumentando a quantidade de nutrientes disponíveis para 0 crescimento e desenvolvimento das culturas (COUTINHO, 2005).

Essa fertilidade, no entanto, é temporária. A rápida infestação dos campos agrícolas por plantas invasoras reduz ainda mais a produtividade dos plantios. Os rendimentos oriundos dos cultivos frequentemente declinam entre um e três anos após a derrubada da floresta. Assim, a cada ano uma nova área de floresta é derrubada e queimada pelas famílias de agricultores carentes da Amazônia para que haja garantia de continuidade na produção de subsistência. Além disso, expõem a superfície do solo à ação erosiva da chuva e do vento (NEPSTAD et al., 1991)..

A produtividade agrícola cai na medida em que a qualidade do solo piora, embora um patamar mais baixo de produtividade possa ser mantido por sistemas tais como a alternância de cultivo. 
As queimadas provocam um uso maior de agrotóxicos e herbicida, para o controle de pragas e de plantas invasoras, sendo que esta prática agrava ainda mais a questão ambiental, afetando os microorganismos do solo e contaminando o lençol freático e os mananciais. A contaminação da água pode atingir níveis de difícil ou até mesmo impossível recuperação (GIGANTE et AL, 2007).

\subsection{Impacto Social}

Os incêndios desgastam a capacidade dos ecossistemas Amazônicos de suportar vida. Por essa razão, afetam toda a sociedade humana.

A fumaça provocada pelas queimadas reduz a visibilidade, provocando acidentes de trânsito e causando o fechamento de aeroportos nas cidades da Amazônia. Em 1996 e 1997, os aeroportos de Rio Branco (Acre), Porto Velho (Rondônia) Imperatriz (Maranhão) e Conceição do Araguaia, Carajás e Marabá (Pará) permaneceram fechados por um total de 420 horas, devido à fumaça.

Os incêndios ainda impõem danos à rede elétrica e, assim, interrompem a transmissão de energia. Em 1995, ocorreram 47 interrupções no fornecimento de energia proveniente da Hidroelétrica de Tucuruí, e custaram à companhia (Eletronorte) aproximadamente US\$2,2 milhões em lucros. A esse custo não são incluídos aqueles impostos às empresas e às casas que foram obrigadas a comprar geradores ou à população em geral, que teve seus alimentos apodrecidos ou perdeu o sono por causa das interrupções de energia (NEPSTAD et al., 1991)

\section{USO DO FOGO NA AMAZÔNIA}

$\mathrm{Na}$ Amazônia, o fogo é um dos instrumentos mais utilizados nas atividades produtivas, pela cultura do corte - queima para a limpeza e transformação da floresta em pastagem. O impacto ambiental das queimadas envolve a fertilidade dos solos, a destruição da biodiversidade, a fragilização de ecossistemas, a destruição de linhas de 
transmissão, a qualidade do ar e de visibilidade, bem como aumento do risco de acidentes em estradas e a limitação do tráfego aéreo, dentre outros aspectos (ACRE, 2010).

O Instituto Brasileiro de Geografia e Estatística (IBGE) registra 600 mil famílias de produtores rurais na Amazônia. Este número expressa a grandeza deste segmento no cenário amazônico, sendo que a maioria dessas famílias usa fogo todos os anos para limpar os pastos.

Grande parte da biodiversidade brasileira está na Amazônia, logo é importante conhecer e avaliar os impactos causados pelas queimadas visto que são amplamente utilizadas pelos produtores da região.

A agricultura de derrubada e queima faz parte das práticas das populações indígenas da Amazônia há milhares de anos. As áreas desmatadas são posteriormente deixadas em pousio na forma de capoeira, como uma estratégia de regeneração da vegetação nativa que permite o acúmulo de carbono e outros nutrientes na biomassa, possibilitando que essas áreas voltem a ser utilizadas para atividades agrícolas após alguns anos (WADT, 2006).

A cultura indígena, do uso do fogo para o manejo das terras agrícolas, foi absorvida em grande escala pelos produtores da Amazônia por considerá-la um meio prático para diversas finalidades, como limpeza do terreno para eliminar restos de cultura; aumento da disponibilidade de nutrientes no solo e, consequentemente, da sua capacidade produtiva; redução da incidência de pragas, de doenças, de gastos com mão de obra para limpeza do terreno; redução dos custos de produção; entre outras (MESQUITA, 2008).

As práticas antigas de agricultura, de corte e queima, permitem o cultivo em solos ácidos e inférteis que dominam grande parte da Amazônia. A queima transforma a biomassa florestal em cinzas ricas em nutrientes que fertilizam o solo. Essa fertilidade, no entanto, é temporária. A rápida infestação dos campos agrícolas por plantas invasoras reduz ainda mais a produtividade dos plantios. Os rendimentos oriundos dos cultivos frequentemente declinam entre um e três anos após a derrubada da floresta. Assim, a cada ano uma nova área de floresta é derrubada e queimada pelas famílias de agricultores carentes da Amazônia para que haja garantia de continuidade na produção de subsistência (NEPSTAD et al, 99). 
Em condições normais, os incêndios realizados de forma rotineira por agricultores e fazendeiros raramente se espalham nas florestas tropicais adjacentes, as quais são muito úmidas para serem queimadas. Mas a seca prolongada, por exemplo, a que foi induzida pelo El Niño em 1998 secou as florestas de Roraima ao ponto de pegarem fogo.

O El Niño é um fenômeno climático que ocorre devido às interações entre o oceano e a atmosfera. Os ventos alísios são ventos que sopram no sentido leste - oeste do oceano pacífico, gerando uma movimentação das águas quentes neste sentido, logo as mesmas são levadas para o leste da Austrália. Durante o El Niño há um enfraquecimento dos ventos alísios fazendo com que as águas quentes do oceano pacífico se concentrem no Peru. Esse fenômeno gera uma série de mudanças climáticas ao longo do globo terrestre (FERREIRA, 2005).

Na Amazônia o El Niño causa um período de estiagem maior que o comum e a seca prolongada, induzida pelo El Niño em 1998, secou as florestas causando muitos focos de incêndio. As chamas foram finalmente extintas pelas chuvas no início de abril de 1998, após terem carbonizado cerca de 3,3 milhões de hectares, dos quais 1 milhão estavam cobertos por floresta tropical (NEPSTAD et al, 99).

Todos os anos grandes áreas de vegetação nativa na Amazônia são perdidos para os incêndios florestais. Mesmo tendo consciência do grande problema que o fogo pode causar, a extinção dessa ferramenta agrícola é muito complicada, pois poucas são as alternativas acessíveis aos pequenos e isolados produtores. Logo, o problema do fogo na Amazônia vai além da fiscalização, pois é necessário o desenvolvimento de novas técnicas que sejam viáveis aos pequenos produtores da região.

\section{CONSIDERAÇÕES FINAIS}

A legislação Brasileira referente ao uso do fogo vem sendo aprimorada ao longo dos anos e apesar de estar avançando, existe uma série de empecilhos culturais para que realmente funcionem. 
O fogo é uma ferramenta básica pela qual os agricultores de subsistência sobrevivem em regiões remotas da floresta e os grandes proprietários de terra reclamam e defendem seus direitos de propriedade também com o uso do fogo.

São inúmeros os impactos causados pelas queimadas e incêndios florestais. O fogo causa danos à vegetação, à fauna, à saúde humana, à produtividade agrícola e ao regime hidrológico. Seus efeitos negativos para o meio ambiente são potencializados na Amazônia Legal.

\section{AGRADECIMENTOS}

Ao Núcleo de Estudos em Pesquisa e Planejamento Ambiental (NEPPA) da Universidade Federal de Lavras (UFLA) pelo apoio técnico-científico e ao CNPq, FAPEMIG e CAPES pelo apoio financeiro.

\section{REFERÊNCIAS}

ACRE. Secretaria de Estado de Meio Ambiente - SEMA. Relatório da Comissão Estadual de Gestão de Riscos Ambientais - CEGdRA. Rio Branco, Acre. Digital. 2010.

BARBOSA, R. I.; FEARNSIDE, P. M. Incêndios na Amazônia brasileira: estimativa da emissão de gases do efeito estufa pela queima de diferentes ecossistemas de Roraima na passagem do evento "El Niño" (1997/98). In: Acta Amazonica 29: 513-534. 1999.

BRASIL. Decreto Federal no 12.651 de 25 de maio de 2012. Institui o Novo Código Florestal Brasileiro. Brasília, DF, 2012. Disponível em <http://www.planalto.gov.br>. Acesso em: 07/08/2013.

Decreto Federal no 23.793 de janeiro de 1934. Decreta o código florestal. Brasília, DF, 1934. Disponível em <http://www.planalto.gov.br>. Acesso em: 07/08/2013.

. Decreto Federal no 4.771 de 15 de setembro de 1965. Institui o código florestal brasileiro. Brasília, DF, 1965. Disponível em <http://www.planalto.gov.br>. Acesso em: 07/08/2013.

BORGES, L. A. C.; REZENDE, J. L. P.; COELHO JÚNIOR, L. M. Áreas de Proteção Ambiental no Interior de Propriedades Rurais - APP e RL. In: Congresso Internacional de Direito Ambiental, 2009, São Paulo. Direito Ambiental, mudanças climáticas e desastres: impactos nas cidades e no patrimônio cultural. São Paulo: Imprensa Oficial do Estado de São Paulo, 2009. v. 2. p. 397-412. 
COUTINHO, A. C. Dinâmica das queimadas no Estado do Mato Grosso e suas relações com as atividades antrópicas e a economia local. Tese (Doutorado em Ciência Ambiental) - Procam, Universidade de São Paulo, 2005. 308 p.

EMBRAPA MONITORAMENTO POR SATÉLITE. Monitoramento Orbital de Queimadas. Campinas, SP.: 1991. Disponível em: <http://www.queimadas.cnpm.embrapa.br>. Acesso em: 16 de agosto de 2013.

FEARNSIDE, P. M. Desmatamento na Amazônia brasileira: história, índices e consequências. Megadiversidade, v.1, n.1, p.113-22, 2005.

FERREIRA, R. N. O que é o El Niño. In: Revista Eco 21, ano XV, № 101 abril/2005.Disponívelem:<http://ambientes.ambientebrasil.com.br/mudancas_climaticas/art igos/o_que_e_o_el_ni\%C3\%B1o.html >. Acesso em: 16 de agosto de 2013.

GIGANTE, L.A.; ZAVALA, A. Z.; PEREIRA, B. D.; SILVA, G. R.; OYAMADA, G. C. Um estudo da similaridade das queimadas entre municípios no estado de mato grosso.In: Sober. XLV Congresso da Sociedade Brasileira de Economia, Administração e Sociologia Rural. Londrina, julho de 2007.

GIL, A. C. Como elaborar projetos de pesquisa. 4. ed. São Paulo: Atlas, 2008.

GONÇALVES, K.S; CASTRO, H.A; HACON, S.S. As queimadas na região amazônica e o adoecimento respiratório. In: Ciência \& Saúde Coletiva. Data de publicação: 01/06/2012.

HOUGHTON, R. Annual Fluxes of Carbon from Deforestation and Regrowth in the Brazilian Amazon. Nature, 403, p: 301-304, 2000.

IBGE (INSTITUTO BRASILEIRO DE GEOGRAFIA E ESTATÍSTICA). Geoestatísticas revelam patrimônio ambiental da Amazônia Legal. In: Comunicação Social. 01 de junho de 2011. Disponível em: < http://www.ibge.gov.br/home/presidencia/noticias/noticia_visualiza.php?id_noticia=1887\&i d_pagina=1>. Acesso em: 13 de agosto de 2013.

MALHOTRA, N. K. Pesquisa de marketing: uma orientação aplicada. 3. ed. Porto Alegre: Bookman, 2001.

MESQUITA, A. G. G. Impactos das queimadas sobre o ambiente e a biodiversidade Acreana. Revista Ramal de Ideias, Rio Branco, v.1, n.1, 2008.

MILORI, D.M.B.P.(2004) Efeito Estufa X Agricultura. Agronline.com.br. Disponível em: <http://www.agronline.com.br/artigos/artigo.php?id=155> Acesso em: 24 de julho de 2013.

MMA- Ministério do Meio Ambiente. Quarto relatório nacional para a Convenção sobre Diversidade Biológica: Brasil. MMA, Brasília. 2011.

NEPSTAD, D. C., C. Uhl e E. A. S. Serrão. 1991. Recuperation of a degraded Amazonian landscape: forest recovery and agricultural restoration. Ambio20 (6): 248 - 255. 
NEPSTAD, D. C.; MOREIRA, A. G.; ALENCAR, A. A. Floresta em Chamas: Origens, Impactos e Prevenção do Fogo na Amazônia. In: Ipam. Programa Piloto para Proteção das Florestas Tropicais do Brasil. Ipam: Brasília; 1999.

NEPSTAD, D.C.; MOREIRA, A.; VERÍSSIMO, A.; LEFEBVRE, P.; SCHLESINGER, P. Forest fires prediction and prevention in the brazilian amazon. Conservation Biology, v. 12, n. 5, p. 951-953, Oct. 1998.

WADT, L. H. VALENTIN, J. F. PEREIRA, J. B. M. Uso do fogo na agricultura do Acre.Agronline.com.br. 2006 Disponível

em: <http://www.agronline.com.br/artigos/artigo.php?id=449>. Acesso em: 24 de julho de 2013. 